\title{
Surgical management of an esophagotracheal fistula as a severe, late complication of repeated endoscopic stenting treatment
}
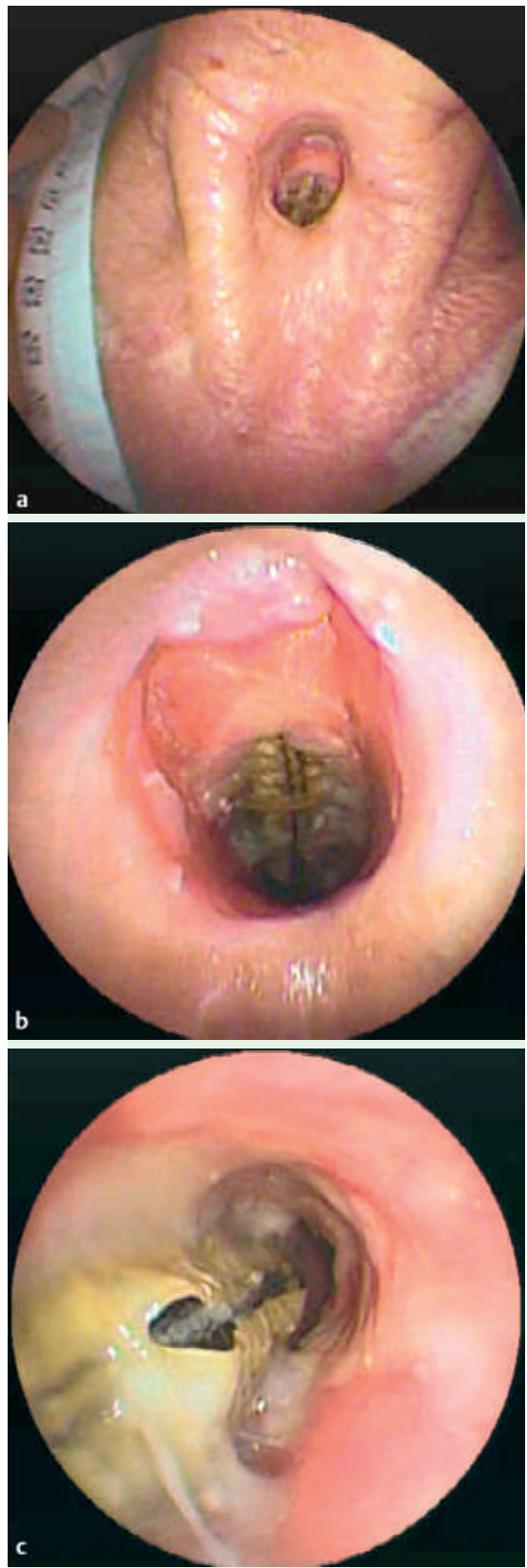

Fig. 1 a, b View through the tracheostoma showing the complete necrosis of the posterior wall of the trachea and the esophageal stent with the broad coating defect. c Compression to $20 \%$ of the tracheal lumen by the protruding esophageal stent.

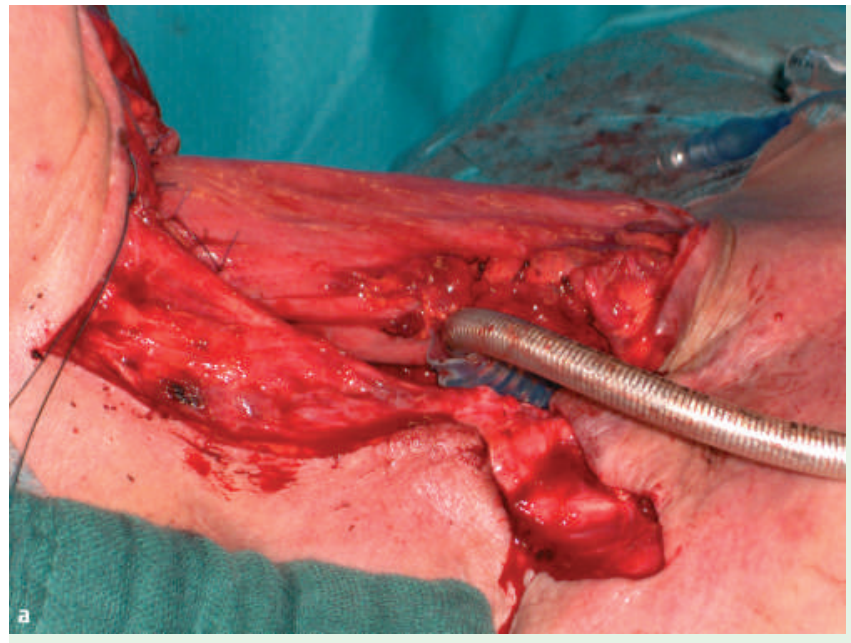

Fig. 2 a, b Reconstruction with a pharyngogastrostomy and a temporary T-tube in the trachea. c Closure of the cervical skin defect with a mesh graft.

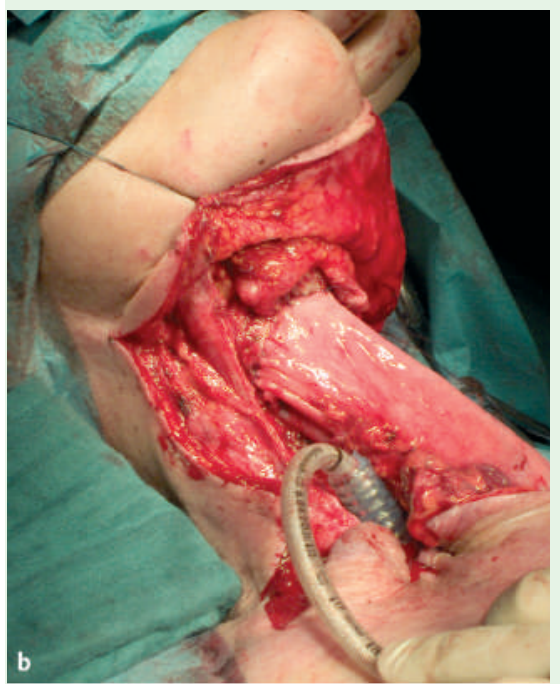

An acquired, nonmalignant esophagotracheal fistula is an uncommon and difficult problem in clinical management. A few reports [1-5] describe various clinical examples and treatment solutions to the problem, but due to the rarity of the problem, guidelines for effective management have not been established.

In 1977, a 29-year-old woman with a thyroid carcinoma underwent thyroidectomy, neck dissection, radioiodine therapy, and telecobalt radiation. In 1997 she presented with dyspnea and dysphagia due to a retrolaryngeal stenosis. She underwent tracheostomy, repeated balloon dilation, and argon plasma coagulation therapy. The tracheostomy could then be removed 1 year later. However, in 2001

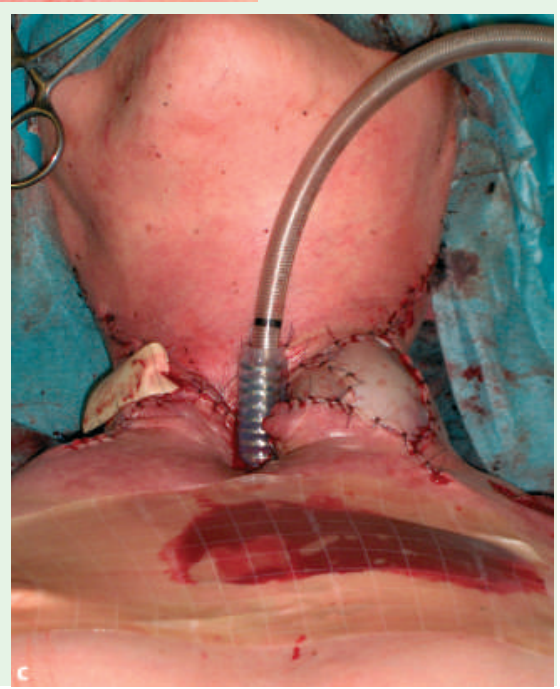

the stenosis relapsed, and placement of a tracheal stent was necessary. In 2003, esophagotracheal fistula and bilateral recurrent laryngeal nerve palsy were first described for this patient. Despite tracheostomy and an esophageal stent, a percutaneous gastrostomy was necessary to enable enteral nutrition. Recurrent overgrown stents were treated by overstenting, but in November 2005 recanalization was no longer possible. Beyond it, a wide esophagotracheal fistula developed with necrosis of the posterior wall of the whole trachea ( $\bullet$ Fig. $\mathbf{1} \mathbf{a}, \mathbf{b}$ ). The stent showed a broad coating defect, with the tracheal lumen compressed to $20 \%$ ( Fig. 1 c). Recurrent scabs and mucus of the respiratory tract with dyspnea 
indicated the necessity for surgery, after recurrence of thyroid cancer was ruled out.

The larynx and trachea were resected and replaced with a tracheal T-tube. After extraction of the esophagus stent, and the resection of the esophagus, the sternoclavicular joints, and the manubrium sterni, the thoracic inlet was then closed with a pedicled sternocleidomastoid muscle, and a retrosternal interposed end-to-side pharyngogastrostomy was performed ( Fig. 2a,b). The cervical skin defect was closed with a mesh graft ( $\bullet$ Fig. 2 c). Acute, postoperative bleeding from the right carotid artery, caused by stent remnants, was stopped by interventional placement of a coated endovascular stent. The T-tube in the trachea was removed 29 days postoperatively, and the patient was discharged on day 42.

Endoscopy_UCTN_Code_CPL_1AH_2AD
R. Ladurner ${ }^{1}$, C. Schulz ${ }^{1}$, P. Jacob ${ }^{1}$, M. Küper ${ }^{1}$, T. Kratt ${ }^{1}$, S. Preyer $^{2}$,

A. Königsrainer ${ }^{1}$

1 Department of General, Visceral and Transplant Surgery, University Hospital Tübingen, Tübingen, Germany

2 Department of Ear, Nose and Throat, University Hospital Tübingen, Tübingen, Germany

\section{References}

1 Baisi A, Bonavina L, Narne S et al. Benign tracheoesophageal fistula: results of surgical therapy. Dis Esophagus 1999; 12: 209-211

2 Freire JP, Feijo SM, Miranda L et al. Tracheoesophageal fistula: combined surgical and endoscopic approach. Dis Esophagus 2006; 19: 36 - 39

3 Mathisen DJ, Grillo HC, Wain JC et al. Management of aquired non-malignant tracheoesophageal fistula. Ann Thorac Surg 1991; 52: 759- 765

4 Reed MF, Mathisen DJ. Tracheoesophageal fistula. Chest Surg Clin N Am 2003; 13: 271-289

5 Wang MQ Sze DY, Wang ZP et al. Delayed complications after esophageal stent placement for treatment of malignant esophageal obstructions and esophagorespiratory fistulas. J Vasc Interv Radiol 2001; 12: $465-474$
Bibliography

DOI 10.1055/s-2007-995325

Endoscopy 2007; 39: E341-E342

(c) Georg Thieme Verlag KG Stuttgart · New York . ISSN 0013-726X

Corresponding author

\section{R. Ladurner, MD}

Department of General, Visceral, and Transplant Surgery

University Hospital Tübingen

Hoppe-Seyler-Str. 3

D-72076 Tübingen

Germany

Fax: +49-7071-29-5588

ruth.ladurner@med.uni-tuebingen.de 